\title{
"Environmental risk factors associated with juvenile idiopathic arthritis associated uveitis: a systematic review of the literature"
}

\author{
Sarah L. N. Clarke ${ }^{1,2,3^{*}}$ (D), Katie S. Mageean ${ }^{3}$, Henry Carlton ${ }^{2}$, Gabriele Simonini ${ }^{4}$, Gemma C. Sharp ${ }^{1,2}$,
} Caroline L. Relton ${ }^{1,2}$ and Athimalaipet V. Ramanan ${ }^{3,5}$

\begin{abstract}
Background: Juvenile idiopathic arthritis associated uveitis (JIA-U) is the most common extra-articular manifestation of juvenile idiopathic arthritis (JIA) and carries considerable risk to vision. The aim of this systematic review was to synthesise evidence of environmental risk factors for JIA-U and identify risk factors which may be modifiable or used to stratify JIA patients.

Methods: This systematic review was carried out in accordance with PRISMA guidelines. Four online databases - Cumulative Index of Nursing and Allied Health Literature, Web of Science, MEDLINE and Embase - were searched from database inception to 12th August 2020. Identified studies were screened by two independent reviewers against pre-defined inclusion and exclusion criteria. Data was extracted from all primary studies meeting inclusion criteria and independently checked.

Results: We identified three studies from 895 unique records which met the inclusion criteria, each examining a different environmental risk factor. This systematic review includes 973 , predominantly female, participants with JIA across these three studies. The use of allergy medication or documentation of "allergy"/"allergic" in the medical records was associated with an increased risk of JIA-U in all models presented. Vitamin D sufficiency was associated with reduced risk of JIA-U. There was insufficient evidence to support an association between seasonality and JIA-U.

Conclusions: This review identifies a potential role for allergy and vitamin D in JIA-U. It also illustrates the paucity of data regarding environmental risk factors for JIA-U and highlights the need for further research to both identify additional risk factors and replicate existing findings.
\end{abstract}

Keywords: Juvenile idiopathic arthritis, Uveitis, Risk factors, Environment, Vitamin D, Season, Allergy

\section{Background}

Juvenile idiopathic arthritis (JIA) is the most common rheumatic condition of childhood and juvenile idiopathic arthritis associated uveitis (JIA-U) is the most common associated extra-articular manifestation. The estimated prevalence of JIA-U in JIA patients is $11-38 \%[1,2]$. However,

\footnotetext{
* Correspondence: sarah.clarke@bristol.ac.uk

'MRC Integrative Epidemiology Unit, University of Bristol, Bristol, UK

${ }^{2}$ Population Health Sciences, Bristol Medical School, University of Bristol, Bristol, UK

Full list of author information is available at the end of the article
}

prevalence varies by JIA subtype with estimates as high as $47 \%$ in oligoarticular JIA [3]. JIA-U is often asymptomatic but carries considerable risk to vision thus children with JIA undergo regular ophthalmic screening [4]. Guidelines for frequency and duration of JIA-U screening are based on existing clinical risk factors of gender, JIA subtype, age of JIA onset, and anti-nuclear antibody (ANA) and HLA-B27 status. However these lack specificity and children may still develop uveitis between screening visits [5].

\section{Springer Open}

(-) The Author(s). 2021 Open Access This article is licensed under a Creative Commons Attribution 4.0 International License, which permits use, sharing, adaptation, distribution and reproduction in any medium or format, as long as you give appropriate credit to the original author(s) and the source, provide a link to the Creative Commons licence, and indicate if changes were made. The images or other third party material in this article are included in the article's Creative Commons licence, unless indicated otherwise in a credit line to the material. If material is not included in the article's Creative Commons licence and your intended use is not permitted by statutory regulation or exceeds the permitted use, you will need to obtain permission directly from the copyright holder. To view a copy of this licence, visit http://creativecommons.org/licenses/by/4.0/. 
JIA-U is considered to be a heterogenous disease, driven by both genetic and environmental factors. There has been increasing literature regarding genetic influences on JIA-U susceptibility [6] and the first genome wide association study of JIA-U has recently been published [7]. It has previously be noted that evidence of external (environmental) triggers for JIA-U is limited and environmental risk factors for all cause uveitis have been summarised [8]. However, the identification of specific risk factors for JIA-U will assist in improving the JIA-U screening programmes as well as potentially redefining treatment strategies for patients based on their individual risk profile. Thus, the aim of this systematic review is to identify environmental risk factors associated with JIA-U incidence which may either be modifiable or assist in risk stratification of JIA patients. To our knowledge this is the first systematic review examining environmental risk factors for JIA-U.

\section{Methods}

This study follows guidance from the Preferred Reporting Items for Systematic Reviews and Meta-analyses (PRISMA) statement [9]. The protocol for this systematic review was pre-registered on PROSPERO (ID: CRD42017078306) [10] and can be accessed at https:// www.crd.york.ac.uk/prospero/display_record.php? Recor$\mathrm{dID}=78,306$.

\section{Literature searching}

Literature searching of online bibliographic databases were carried out in order to identify literature on environmental risk factors associated with JIA-U. Expert advice from a database searching specialist was sought prior to designing the search strategy. Each search was carried out in four databases; MEDLINE and Embase via Ovid, Web of Science (WOS) via Clarivate Analytics and Cumulative Index of Nursing and Allied Health Literature (CINAHL) via EBSCOhost. Searches included literature from database inception until 12th August 2020. Table 1 shows the search strategy that was used for MEDLINE; the syntax was amended for use in other databases. All searches were limited to studies in English only.

\section{Study selection}

References (including abstracts where available) were downloaded into Endnote X9 (Clarivate Analytics) and duplicates were removed. All unique references were uploaded to Rayyan [11] and underwent title and abstracts screening by two independent reviewers (SC and $\mathrm{KM} / \mathrm{HC}$ ) against the inclusion and exclusion criteria listed in Table 2 . The full texts of potentially relevant studies identified during title and abstract screening were retrieved. These articles were again independently screened by two reviewers ( $\mathrm{SC}$ and $\mathrm{KM} / \mathrm{HC}$ ). Bibliographies of review articles were also hand-searched to identify other potentially relevant studies and expert advice was sought from AR regarding key studies which may not have been captured within our searches. Any discrepancies during screening were resolved by discussion and/or involvement of the third reviewer (AR). Where a study was felt to be highly relevant but key inclusion/exclusion criteria were not reported, study authors were contacted prior to a final decision being made.

\section{Data extraction}

A data extraction form was created and piloted in Microsoft Excel by SC and KM. Data was extracted from each eligible study by SC and independently checked by KM/HC. Data extraction consisted of:

- First author

- Study title

- Year of publication

- Study country

- Participant demographic characteristics

- Sample size

- Diagnostic criteria used

- Length of follow-up

- Outcomes

- Event rates for unexposed/exposed cases and controls

- Risk factors listed in univariate and multivariate analyses

- Covariates adjusted for in analysis

- Source of risk factor ascertainment

- JIA and JIA-U subtypes included

- Newcastle-Ottawa scale scores

For consistency between studies, the extracted sample size was the sample size of the largest analysis undertaken within a study. All data is presented as odds ratio and $95 \%$ confidence intervals where possible.

\section{Risk of bias (quality) assessment}

The methodological quality and risk of bias of included studies was assessed using the Newcastle-Ottawa Scale (NOS) for case-control and cohort studies [12]. Studies were independently scored by SC and $\mathrm{KM} / \mathrm{HC}$ and any discrepancies were resolved by discussion and/or involvement of a third reviewer (AR). A risk of biases table was created summarising the star rating of included studies (maximum score of 9 stars reflecting the highest quality).

\section{Data synthesis}

None of the included studies examined overlapping risk factors, thus there was no data suitable for the quantitative meta-analysis. Therefore, as specified in our proto$\mathrm{col}$, the data within this systematic review is synthesised 
Table 1 Search strategy for MEDLINE by OVID (syntax amended for use in other databases)

\begin{tabular}{|c|c|}
\hline 1 & (juvenile adj2 arthritis).tw \\
\hline 2 & Arthritis, Juvenile/ \\
\hline 3 & Uveitis/ \\
\hline 4 & uveitis.tw \\
\hline 5 & iridocyclitis.tw \\
\hline 6 & inflammat* ocul*.tw \\
\hline 7 & inflammat* eye.tw \\
\hline 8 & non-infectious uveitis.tw \\
\hline 9 & autoimmune uveitis.tw \\
\hline 10 & Risk Factors/ \\
\hline 11 & Environment/ \\
\hline 12 & Seasons/ \\
\hline 13 & Postpartum Period/ \\
\hline 14 & Pregnancy/ \\
\hline 15 & Birth order/ \\
\hline 16 & age factors/ or maternal age/ \\
\hline 17 & paternal age/ \\
\hline 18 & Socioeconomic Factors/ \\
\hline 19 & Demography/ \\
\hline 20 & Infection/ \\
\hline 21 & Communicable Diseases/ \\
\hline 22 & Bacterial Infections/ \\
\hline 23 & risk.tw \\
\hline 24 & environmen*.tw \\
\hline 25 & perinatal.tw \\
\hline 26 & (season* adj3 birth).tw \\
\hline 27 & smok*.tw \\
\hline 28 & virus.tw \\
\hline 29 & 1 or 2 \\
\hline 30 & 3 or 4 or 5 or 6 or 7 or 8 or 9 \\
\hline 31 & $\begin{array}{l}10 \text { or } 11 \text { or } 12 \text { or } 13 \text { or } 14 \text { or } 15 \text { or } 16 \text { or } 17 \text { or } 18 \text { or } 19 \text { or } 20 \text { or } 21 \\
\text { or } 22 \text { or } 23 \text { or } 24 \text { or } 25 \text { or } 26 \text { or } 27 \text { or } 28\end{array}$ \\
\hline 32 & 29 and 30 and 31 \\
\hline
\end{tabular}

in narrative form. The principal summary measure for this systematic review is unadjusted and adjusted odds ratio. Where this was not reported by a study, or was not possible to derive from the raw data presented within a study, we used the study reported summary measure for data synthesis.

\section{Results}

\section{Study selection}

Searches of CINAHL, Embase, MEDLINE and WOS on 12th August 2020 identified 1314 JIA-U studies. After collation, 419 studies were identified as duplicates by Endnote X9. The majority of studies were excluded during title and abstract screening. In total, 67 studies were assessed in full and of these, three studies met the inclusion criteria listed in Table 2. The flowchart for selection of included studies and specific reasons for exclusion is shown in Fig. 1.

\section{Characteristics of included studies}

The characteristics of the three included studies are shown in Table 3. All studies were retrospective cohort studies. Due to publication date and country of origin, the studies are presumed to encompass non-overlapping samples thus this systematic review includes a total sample size of 973 participants. All studies reported female predominance to JIA-U within the JIA population. Cole et al [14] and Sengler et al [15] reported statistically significant differences in the mean age of JIA onset between JIA-U cases and controls; patients who developed JIA-U had younger age of JIA onset. Zulian et al [13] also reported a lower mean age of JIA onset in patient who developed mild JIA-U however this did not reach statistical significance. All three studies utilised different JIA and JIA-U diagnostic criteria and included different JIA subtypes.

\section{Quality assessment and risk of bias}

The NOS score of the included studies ranged from five to seven, with the full breakdown of NOS scores shown in Table 4. All studies lost points for the length of participant follow-up.

\section{Environmental risk factors}

Three environmental risk factors from three studies were examined - seasonality, allergy and vitamin $\mathrm{D}$, see Table 5. Of these, only seasonality was reported in an unadjusted model; unadjusted estimates were not reported for allergy and vitamin $\mathrm{D}$, nor was sufficient raw data provided in the studies to derive this estimate. Zulian et al [13] reported winter to be associated with an increased risk of JIA-U, autumn and spring to be associated with a decreased risk of JIA-U and summer to show no association with JIA-U. The confidence interval around these estimates were not reported, nor was sufficient event rate data available to derive these. In all cases, the $p$ value was $>0.05$ (exact values not reported), providing insufficient evidence to support an association between seasonality and JIA.

Both allergy and vitamin D were examined in an adjusted model. Cole et al [14] reported the association between allergy and JIA-U by examining the documentation of "allergy" or "allergic" within the clinical records, and the documented use of allergy medication. Bivariate analysis demonstrated that "allergy" or "allergic" in the medical records, and the use of allergy medications were all associated with an increased risk of 
Table 2 Inclusion and exclusion criteria for studies

\begin{tabular}{|c|c|c|}
\hline Domain & Inclusion criteria & Exclusion criteria \\
\hline $\begin{array}{l}\text { Study } \\
\text { language }\end{array}$ & English & Not English \\
\hline Study type & $\begin{array}{l}\text { Systematic review } \\
\text { Observation study (cohort, case-control, cross-sectional) }\end{array}$ & $\begin{array}{l}\text { Non-systematic review article } \\
\text { Clinical trial } \\
\text { Animal study } \\
\text { In vitro study } \\
\text { Ex vivo study } \\
\text { Case report }\end{array}$ \\
\hline $\begin{array}{l}\text { Study } \\
\text { population }\end{array}$ & $\begin{array}{l}\text { Patients with juvenile idiopathic arthritis associated uveitis (JIA-U), diagnosed using any } \\
\text { recognised uveitis diagnostic criteria [e.g. International Uveitis Study Group (IUSG), } \\
\text { Standardised Uveitis Nomenclature (SUN), International Classification of Diseases (ICD)] } \\
\text { who also meet diagnostic criteria for juvenile idiopathic arthritis (JIA), diagnosed using } \\
\text { any recognised criteria [e.g. American College of Rheumatology (ACR), EULAR }{ }^{\prime \prime} \\
\text { International League of Associations for Rheumatology (ILAR), ICD] } \\
\text { PLUS } \\
\text { Onset of disease at or before } 16 \text { years of age }\end{array}$ & Adults (defined as age > $16 \mathrm{yrs}$ ) \\
\hline $\begin{array}{l}\text { Study } \\
\text { comparator }\end{array}$ & General population without JIA or JIA-U & $\begin{array}{l}\text { Other rheumatic, autoimmune or } \\
\text { inflammatory disease }\end{array}$ \\
\hline $\begin{array}{l}\text { Study risk } \\
\text { factor }\end{array}$ & Environmental risk factors (including patient, familial and perinatal) & $\begin{array}{l}\text { Non-environmental risk factors (e.g. genetic, } \\
\text { ethnic/racial, familial aggregation) }\end{array}$ \\
\hline
\end{tabular}

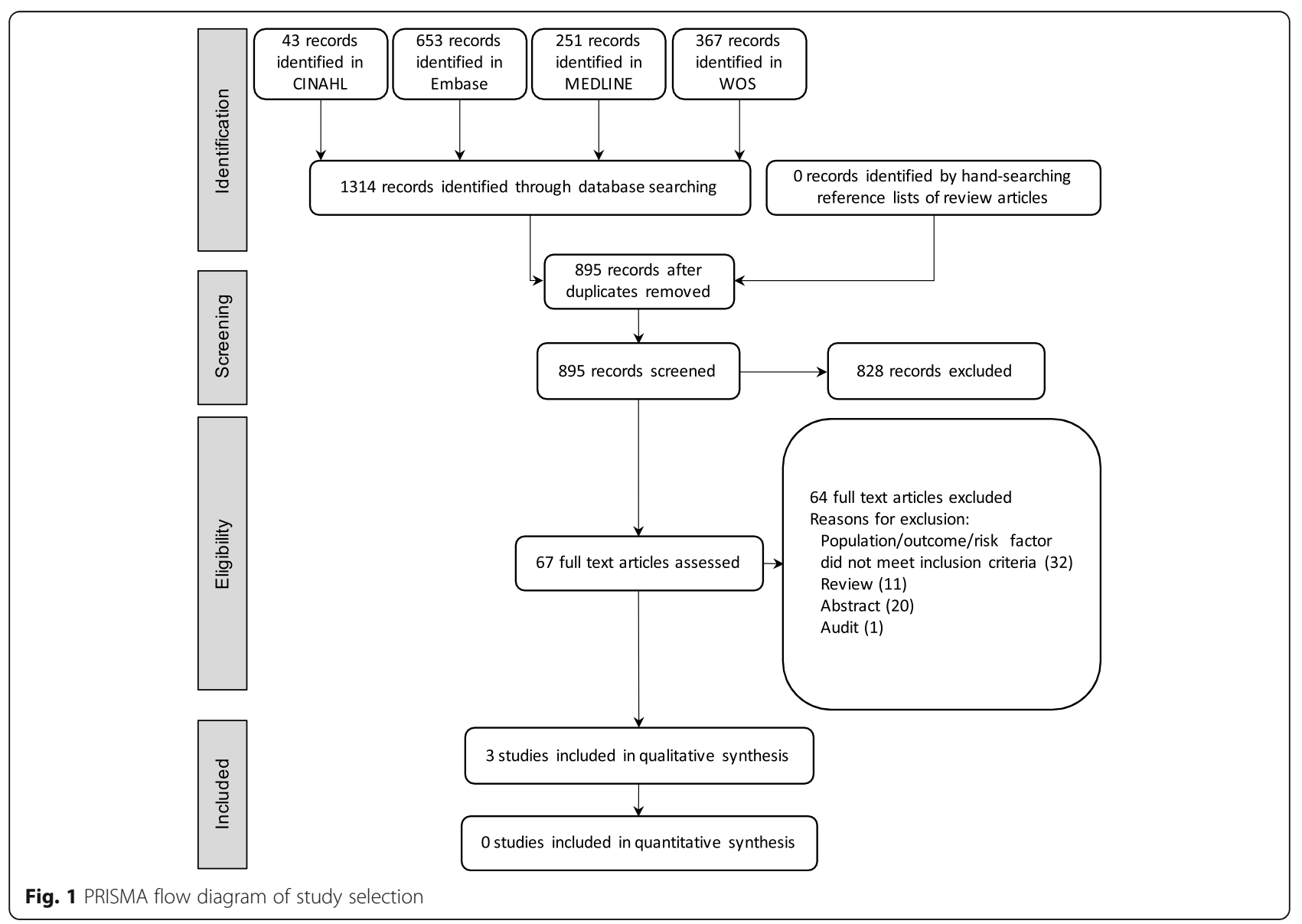


Table 3 Characteristics of included studies. *Demographic data for this study was stratified by uveitis severity. ICD, International Classification of Diseases, ILAR, International League of Associations for Rheumatology; IUSG, International Uveitis Study Group; JIA, juvenile idiopathic arthritis, JIA-U, juvenile idiopathic arthritis associated uveitis; SD, standard deviation; SUN, Standardisation of Uveitis Nomenclature

\begin{tabular}{|c|c|c|c|c|c|c|c|c|c|c|c|}
\hline Study & $\begin{array}{l}\text { Study } \\
\text { type }\end{array}$ & Country & $\begin{array}{l}\text { Sample } \\
\text { size }\end{array}$ & $\begin{array}{l}\text { Age of } \\
\text { JIA onset, } \\
\text { cases } \\
\text { (mean } \pm \\
\text { SD, } \\
\text { years) }\end{array}$ & $\begin{array}{l}\text { Age of JIA } \\
\text { onset, } \\
\text { controls } \\
\text { (mean } \pm \\
\text { SD, years) }\end{array}$ & $\begin{array}{l}\text { Sex of } \\
\text { cases } \\
\text { (Female, } \\
\% \text { ) }\end{array}$ & $\begin{array}{l}\text { Sex of } \\
\text { controls } \\
\text { (Female, } \\
\% \text { ) }\end{array}$ & Risk factors & $\begin{array}{l}\text { Diagnostic } \\
\text { criteria }\end{array}$ & $\begin{array}{l}\text { JA subtypes } \\
\text { included }\end{array}$ & $\begin{array}{l}\text { JIA-U } \\
\text { subtypes } \\
\text { included }\end{array}$ \\
\hline $\begin{array}{l}\text { Zulian, } \\
2002 \\
{[13]}\end{array}$ & Cohort & Italy & 316 & $\begin{array}{l}2.42 \pm 1.5 \\
(\text { mild)* } \\
3.17 \pm 1.75 \\
\text { (severe) }^{*}\end{array}$ & $3.08 \pm 1.75$ & $\begin{array}{l}89.01 \\
(\text { mild)*, } \\
74.36 \\
\text { (severe)* }\end{array}$ & 78.26 & Seasonality & $\begin{array}{l}\text { ILAR-1997, } \\
\text { IUSG } 1987\end{array}$ & $\begin{array}{l}\text { Oligoarticular } \\
\text { JAA only }\end{array}$ & $\begin{array}{l}\text { No/mild/ } \\
\text { severe uveitis }\end{array}$ \\
\hline $\begin{array}{l}\text { Cole, } \\
2013 \\
{[14]}\end{array}$ & Cohort & USA & 297 & 7.2 & 10.2 & 76.19 & 65.10 & $\begin{array}{l}\text { "Allergy" or } \\
\text { "Allergic" in } \\
\text { medical } \\
\text { records, } \\
\text { allergy } \\
\text { medication } \\
\text { use }\end{array}$ & ICD-9 & $\begin{array}{l}\text { All (ICD-9 } \\
\text { codes 696.0, } \\
714.0,714.2 \\
714.3,714.9 \\
720.2,720.9)\end{array}$ & $\begin{array}{l}\text { Acute and } \\
\text { chronic } \\
\text { iridocyclitis } \\
\text { (ICD-9 codes } \\
364.00 \text { and } \\
364.10 \text { ) }\end{array}$ \\
\hline $\begin{array}{l}\text { Sengler, } \\
2018 \\
{[15]}\end{array}$ & Cohort & Germany & 360 & $4.0 \pm 2.9$ & $7.8 \pm 4.6$ & 73.7 & 66.2 & Vitamin D & $\begin{array}{l}\text { ILAR 2001, } \\
\text { SUN } 2005\end{array}$ & All & Any \\
\hline
\end{tabular}

JIA-U (Table 5). The use of allergy medication was also reported to be associated with increased risk of JIA-U (OR 2.54, 95\% CI 1.22-5.40) in a model adjusted for race, gender, age, oligoarticular subtype, ANA, rheumatoid factor (RF) and psoriasis. Sengler et al [15] investigated the risk of JIA-U according to vitamin D status. They reported the risk of JIA-U to be inversely correlated with mean vitamin D level in a multivariable model (HR 0.95, 95\% CI 0.91-0.99) adjusted for methotrexate use and existing uveitis risk factors (including at JIA onset, female sex, oligoarticular JIA, and ANA positivity). This association persisted when the study population was restricted to those participants for whom vitamin D status was measured prior to JIA-U onset.

\section{Discussion}

The literature search strategy was designed to capture environmental risk factors for JIA-U in the broadest sense and identify all relevant literature regarding JIA-U risk. Nevertheless, the identification of only three studies highlights the unmet research need in this area.

The demographic characteristics of the included studies illustrate that they are representative of the JIA community; JIA-U is reported to be more common in younger, female JIA patients as is seen here. The NOS scores of the studies suggest the studies are of generally of good quality. However, all studies lost points for failing to meet adequate follow-up; length of follow up was reported to be 3 years by Sengler et al and a minimum of 2 years by Zulian et al, but was not reported in the study by Cole et al. The natural history of JIA-U suggests that $90 \%$ of JIA patients develop JIA-U within the first 4 years after JIA diagnosis $[16,17]$. Thus, risk factor studies in JIA-U should ideally follow up participants for at least this period of time. These findings are likely to reflect the challenges of performing robust studies in rare diseases where patient cohorts are small and where appropriate datasets to identify and analyse risk factors robustly may be lacking or limited.

JIA-U is generally considered to be a complex disease, influenced by both genetic and environmental risk factors. The use of broad literature search terms used in this systematic review captured 692 de-duplicated records yet identified only three studies which met the inclusion criteria. Correspondingly we only identified three environmental risk factors which had been examined with regards to JIA-U incidence, none of which overlapped sufficiently to enable statistical comparison. Whilst the primary limitation to performing metaanalysis was lack of replicated risk factors, it should be noted that the included studies used different criteria to ascertain JIA cohorts and define JIA-U status. A number of different criteria have been defined and amended to diagnose JIA over the past 50 years [18] alongside ongoing revisions of the ICD codes. Furthermore, uveitis criteria have also evolved over this time [19]. These factors make the synthesis of historic data challenging and should be considered in planning future studies.

There is increasing recognition of the seasonal variation in both the incidence and disease activity of a number of autoimmune diseases. However, the influence of seasonality on autoimmunity is likely complex and multifactorial. Seasonal variation is observed with a number of factors such as infections, ultraviolet light 


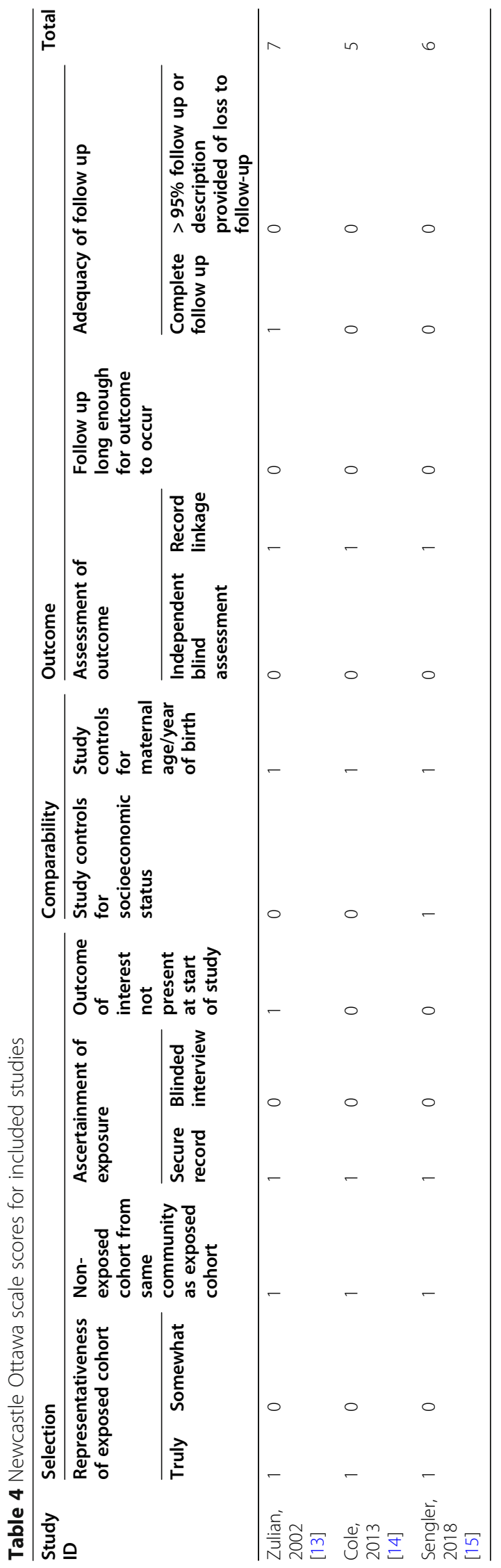


Table 5 Risk factors associated with JIA-U. ${ }^{a}$ reported point estimate, ${ }^{\text {b }}$ confidence intervals not reported, p-value $>0.05$, 'adjusted for race and gender, ${ }^{d}$ adjusted for race, gender, age, oligo subtype, ANA, RF, psoriasis, ${ }^{e}$ reported as HR, ${ }^{f}$ adjusted for MTX and uveitis risk factors (age of JIA onset, female sex, oligoarticular JIA and ANA positivity), ${ }^{9}$ when analysed by patients who were sampled prior to uveitis diagnosis the results were HR 0.95, 95\% Cl 0.92-1.00. ANA, anti-nuclear antibody; Cl, Confidence interval; HR, hazard ratio; MTX, methotrexate; NR, not reported; OR, odds ratio; RF, rheumatoid factor; 25(OH) D, 25-hydroxyvitamin D

\begin{tabular}{|c|c|c|c|c|c|}
\hline Study ID & $\begin{array}{l}\text { Risk } \\
\text { factor }\end{array}$ & Definition & $\begin{array}{l}\text { Univariate OR }(95 \% \\
\text { Cl) }\end{array}$ & $\begin{array}{l}\text { Bivariate OR }(95 \% \\
\text { Cl) }\end{array}$ & $\begin{array}{l}\text { Multivariable OR }(95 \% \\
\text { CI) }\end{array}$ \\
\hline \multirow{4}{*}{$\begin{array}{l}\text { Zulian, } 2002 \\
\text { [13] }\end{array}$} & Seasonality & Autumn & $0.85^{\mathrm{a}, \mathrm{b}}$ & NR & NR \\
\hline & & Summer & $1.00^{a, b}$ & NR & NR \\
\hline & & Winter & $1.39^{\mathrm{a}, \mathrm{b}}$ & NR & NR \\
\hline & & Spring & $0.96^{a, b}$ & NR & NR \\
\hline \multirow[t]{3}{*}{ Cole, 2013 [14] } & Allergy & "Allergy" in clinical notes & NR & $2.14(1.08-4.27)^{c}$ & $N R$ \\
\hline & & "Allergic" in clinical notes & $N R$ & $2.68(1.34-5.55)^{c}$ & $N R$ \\
\hline & & Any allergy medication & NR & $2.92(1.47-5.91)^{c}$ & $2.54(1.22-5.4)^{d}$ \\
\hline $\begin{array}{l}\text { Sengler, } 2018 \\
{[15]}\end{array}$ & Vitamin D & $\begin{array}{l}1 \mathrm{ng} / \mathrm{mL} \text { increase in } 25(\mathrm{OH}) \mathrm{D} \text { level }>22.1 \\
\mathrm{ng} / \mathrm{mL}\end{array}$ & $N R$ & $N R$ & $0.95(0.91-0.99)^{\mathrm{e}, \mathrm{f}, \mathrm{g}}$ \\
\hline
\end{tabular}

exposure, vitamin D and melatonin [20]. Winter is associated with viral respiratory pathogens, spring is associated with bacterial respiratory pathogens such as Mycoplasma pneumoniae [21] and late summer/early autumn is associated with increased prevalence of viral pathogens such as Enterovirus [22]. Seasonal viral infections are postulated to contribute to autoimmunity via mechanisms such as molecular mimicry, epitope spreading and bystander activation [23]. In addition, seasonal sunlight exposure markedly influences vitamin D levels [24], which peak in the summer/autumn and reach a nadir in the winter. Vitamin D has a number of effects on immune function [25] though evidence for hypovitaminosis $\mathrm{D}$ as a risk factor for autoimmune disease incidence, with the exception of multiple sclerosis, is limited. Nevertheless the finding of an association between vitamin D and JIA-U is also supported by a study examining the role of vitamin D in non-infectious uveitis in adults (sample size 3348 ) which found a $21 \%$ reduction in uveitis risk with normal versus low vitamin $D$ levels $(\leq 20 \mathrm{ng} / \mathrm{mL})$ [26]. Whilst this uveitis cohort does not specifically examine JIA-U, it includes participants with other T-cell driven uveitides. Furthermore, the concordant directions of effect seen in the association between seasonality and JIA-U add strength to the association with vitamin D; Zulian et al [13] found autumn to be associated with decreased risk of JIA-U and winter to be associated with an increased risk of JIA-U (albeit in univariate analysis with a $p$-value $>0.05$ ) and Sengler et al [15] reported vitamin D sufficiency to be significantly associated with decreased risk of JIA-U. There are a number of possible reasons for these findings; hypovitaminosis D may itself be a risk factor for JIA-U, it may be a marker of another seasonal exposure, or several seasonal factors may act in combination (e.g. hypovitaminosis D and an infectious agent). Additionally, these associations may be spurious findings given the limited data seen here. Further studies to corroborate and delineate these associations, and allow metaanalysis of the results are warranted. However, such studies are challenging; the asymptomatic nature and insidious onset of JIA-U means the vitamin D level or season at diagnosis may not reflect the vitamin D level or season at JIA-U onset. This temporality needs consideration when designing future studies, which should ideally take place in the context of regular and frequent ophthalmic screening.

Traditionally allergy and autoimmunity were felt to represent different facets of a perturbed immune system under the Th1/Th2 paradigm - with autoimmune diseases presenting in those with a more $\mathrm{T}$ helper cell type 1 (Th1) predisposition and allergies presenting in those with a more $\mathrm{T}$ helper cell type 2 (Th2) predisposition $[27,28]$. However, this paradigm has been challenged in more recent years with the discovery of Th17 cells [29]. Recent data has been shown that rather than being protective, patients with allergic and atopic conditions are at increased risk of developing autoimmunity [30]. We found limited data on the association between allergy and JIA-U, however the direction and magnitude of this association is comparable with estimates of other allergy/atopy/autoimmune associations reported by Krishna et al [30]. Given the immunopathogenic basis of allergic/atopic and autoimmune diseases, it is difficult to ascertain whether associations between these two disease types are evidence of a causal relationship (and in which direction) or whether this association is a correlation due to, for example, underlying perturbation of immune function. Nevertheless, given the increasingly recognised association between autoimmune and allergic traits, 
further studies and resultant meta-analyses in JIA-U may provide support for clinicians to highlight JIA patients with increased JIA-U risk based on their allergy status.

The reasons for the high incidence of uveitis in patients with JIA are poorly understood. Whilst identification and examination of the environmental risk factors overlapping JIA and JIA-U is outside of the scope of this study, a recent review of environmental determinants of JIA [31] reported unclear associations between JIA and the risk factors described here. This study provides an important step in identifying shared and distinct environmental influences on JIA and JIA-U, understanding their role in the aetiopathogenesis of these two conditions and designing future studies.

The main strength of this systematic review is its methodology, which was carried out in accordance with PRISMA guidelines [9] with the associated protocol pre-registered on PROSPERO. Since we anticipated limited published data, we sought advice from a database searching specialist to ensure our search syntax was as broad as possible. We handsearched the reference lists of excluded review articles and used expert opinion to ensure key studies in the field had been captured within our database searches. All stages of screening, data extraction and risk of bias assessment involved a second reviewer. The resource availability for this review necessitated that English language limits were placed on our search strategy, thus it is possible that relevant literature published in another language was not identified. However, the literature included in this review supports the epidemiological data that JIAU is most common in Europe and North America [32]. Since our protocol only allowed for inclusion of full text peer-reviewed articles rather than abstracts/conference proceedings it is possible that relevant 'grey literature' was not included. During full text review, 20/67 studies were excluded as data was only available as a conference abstract. Six of these had readily identifiable peer-reviewed manuscripts which were also captured within our database searches. From the data or cohorts presented in the remaining 14 conference abstracts it appears possible that a number of these formed part of a larger dataset which was subsequently published however we cannot be certain. It seems likely that the number of studies that appear only in the 'grey literature' (i.e. not published in peerreviewed journal articles) is likely to be small, however we cannot fully exclude the potential for publication bias. We restricted our study inclusion to those studies examining JIA-U incidence and subsequently limited our data extraction to the same - further work will be required to evaluate the role of environmental risk factors in JIA-U disease activity and/or severity.

\section{Conclusion}

Whilst JIA-U is considered a complex disease influenced by genetics and the environment, this systematic review identified a very limited number of studies investigating environmental risk factors and their association with JIA-U incidence, thus illustrating a paucity of research in this area. The data available suggest an association between JIA-U and vitamin D, and JIA-U and allergy/allergy medications however these results must be interpreted with caution as they represent the output of single studies. Further studies are needed to strengthen the evidence of these associations and explore their contexts.

A co-ordinated and collaborative effort is needed to identify JIA patient cohorts that not only have sufficient ophthalmic follow-up data over a prolonged period to accurately discern JIA-U case status, but that can also analyse putative patient risk factors whilst accounting for potential confounding. International partnerships are likely to be required to generate enough studies to enable meta-analysis of supposed JIA-U risk factors. Undertaking such work to detect JIA patients with modifiable JIA-U risk factors or identify those who may be at particularly increased risk compared to the current accepted JIA-U risk profile would be of considerable benefit to patients and allow more efficient use of health resources for screening.

\section{Abbreviations}

ANA: Antinuclear antibody; CINAHL: Cumulative Index of Nursing and Allied Health Literature; JIA: Juvenile idiopathic arthritis; JIA-U: Juvenile idiopathic arthritis associated uveitis; NOS: Newcastle Ottawa Scale; PRISMA: Preferred Reporting Items for Systematic Reviews and Meta-analyses; RF: Rheumatoid factor; Th1: T helper cell type 1; Th2: T helper cell type 2; WOS: Web of Science

\section{Acknowledgements}

The authors wish to acknowledge Catherine Borwick (Information Specialist, University of Bristol) for her assistance during the design of search strategies for this review.

\section{Authors' contributions}

SLNC designed this study. SLNC, CLR, GCS, GS and AVR critically revised the study protocol. SLNC, KSM and HC were involved in study screening and data acquisition/ checking. SLNC performed the data analysis/interpretation and wrote the draft manuscript. All authors critically revised and approved the final manuscript.

\section{Funding}

This research was funded in whole, or in part, by the Wellcome Trust [203918/Z/16/Z to SLNC]. For the purpose of Open Access, the author has applied a CC BY public copyright licence to any Author Accepted Manuscript version arising from this submission.

This work is also supported by the Medical Research Council and the University of Bristol [MC_UU_00011/5 to CLR]. The funders had no input in the protocol design or the undertaking of this systematic review.

Availability of data and materials

All data generated or analysed during this study are included in this published article. 


\section{Declarations}

Ethics approval and consent to participate.

Not applicable.

\section{Consent for publication}

Not applicable.

\section{Competing interests}

SLNC - none declared.

KSM - none declared.

$\mathrm{HC}$ - none declared.

GS - has received speaker fees/Honoraria from Abbvie, and Novartis.

GCS - none declared.

$\mathrm{CLR}$ - none declared.

AVR - has received speaker fees/honoraria/consultancy from Abbvie, Eli Lilly, Pfizer, Roche, SOBI, Novartis and UCB.

\section{Author details}

'MRC Integrative Epidemiology Unit, University of Bristol, Bristol, UK. ${ }^{2}$ Population Health Sciences, Bristol Medical School, University of Bristol, Bristol, UK. ${ }^{3}$ Department of Paediatric Rheumatology, Bristol Royal Hospital for Children, Bristol, UK. ${ }^{4}$ Rheumatology Unit, Meyer Children Hospital, NEUROFARBA Department, University of Florence, Florence, Italy. ${ }^{5}$ Translational Health Sciences, Bristol Medical School, University of Bristol, Bristol, UK.

Received: 4 March 2021 Accepted: 10 May 2021

Published online: 24 May 2021

\section{References}

1. Angeles-Han ST, Pelajo CF, Vogler LB, Rouster-Stevens K, Kennedy C, Ponder L, McCracken C, Lopez-Benitez J, Drews-Botsch C, Prahalad S, The CARRA Registry Investigators (2013) Risk markers of juvenile idiopathic arthritis-associated uveitis in the childhood arthritis and rheumatology research Alliance (CARRA) registry. J Rheumatol 40(12):2088-2096. https:/doi.org/10.3899//rheum.130302

2. Moradi A, Amin RM, Thorne JE (2014) The role of gender in juvenile idiopathic arthritis-associated uveitis. J Ophthalmol 2014:461078

3. Packham JC, Hall MA (2002) Long-term follow-up of 246 adults with juvenile idiopathic arthritis: social function, relationships and sexual activity. Rheumatology. 41(12):1440-1443. https://doi.org/10.1093/rheumatology/41.12.1440

4. British Society for Paediatric and Adolescent Rheumatology, Royal College of Ophthalmology. Guidelines for Screening for Uveitis in Juvenile Idiopathic Arthritis. 2006

5. Clarke SL, Sen ES, Ramanan AV (2016) Juvenile idiopathic arthritis-associated uveitis, Pediatr Rheumatol Online J 14(1):27. https://doi.org/10.1186/s12969-016-0088-2

6. Sen ES, Ramanan AV (2019) Juvenile idiopathic arthritis-associated uveitis. Clin Immunol 211:108322

7. Haasnoot AJW, Schilham MW, Kamphuis S, Hissink Muller PCE, Heiligenhaus A, Foell D et al (2018) Identification of an amino acid motif in HLA-DRbeta1 that distinguishes uveitis in patients with juvenile idiopathic arthritis. Arthritis Rheumatol 70(7):1155-1165. https://doi.org/10.1002/art.40484

8. Kalinina Ayuso V, Makhotkina N, van Tent-Hoeve M, de Groot-Mijnes JD, Wulffraat NM, Rothova A et al (2014) Pathogenesis of juvenile idiopathic arthritis associated uveitis: the known and unknown. Surv Ophthalmol 59(5): 517-531. https://doi.org/10.1016/j.survophthal.2014.03.002

9. Moher D, Liberati A, Tetzlaff J, Altman DG, Group P (2009) Preferred reporting items for systematic reviews and meta-analyses: the PRISMA statement. J Clin Epidemiol 62(10):1006-1012. https://doi.org/10.1016/j.jclinepi.2009.06.005

10. Clarke S, Mageean K, Ramanan AV, Simonini G (2017) Environmental risk factors associated with juvenile idiopathic arthritis and juvenile idiopathic arthritis associated uveitis [Available from: https://www.crd.york.ac.uk/ prospero/display_record.php? RecordID=78306]

11. Ouzzani M, Hammady H, Fedorowicz Z, Elmagarmid A (2016) Rayyan-a web and mobile app for systematic reviews. Syst Rev 5(1):210. https://doi.org/1 0.1186/s13643-016-0384-4

12. Wells $G$, Shea B, O'Connell D, Peterson J, Welch V, Losos M, et al., The Newcastle-Ottawa Scale (NOS) for assessing the quality of nonrandomised studies in meta-analyses. http://www.ohrica/programs/clinical_ epidemiology/oxfordasp. Accessed 2021
13. Zulian F, Martini G, Falcini F, Gerloni V, Zannin ME, Pinello L, Fantini F, Facchin P (2002) Early predictors of severe course of uveitis in oligoarticular juvenile idiopathic arthritis. J Rheumatol 29(11):2446-2453

14. Cole TS, Frankovich J, Iyer S, LePendu P, Bauer-Mehren A, Shah NH (2013) Profiling risk factors for chronic uveitis in juvenile idiopathic arthritis: A new model for EHR-based research. Pediatr Rheumatol 11(1) (no pagination)(45)

15. Sengler C, Zink J, Klotsche J, Niewerth M, Liedmann I, Horneff G et al (2018) Vitamin $D$ deficiency is associated with higher disease activity and the risk for uveitis in juvenile idiopathic arthritis - Data from a German inception cohort. Arthritis Res Ther 20(1)

16. Heiligenhaus A, Niewerth M, Ganser G, Heinz C, Minden K, German Uveitis in Childhood Study Group (2007) Prevalence and complications of uveitis in juvenile idiopathic arthritis in a population-based nation-wide study in Germany: suggested modification of the current screening guidelines. Rheumatology (Oxford) 46(6):1015-1019

17. Kotaniemi K, Kautiainen H, Karma A, Aho K (2001) Occurrence of uveitis in recently diagnosed juvenile chronic arthritis: a prospective study. Ophthalmology 108(11): 2071-2075. https:/doi.org/10.1016/S0161-6420(01)00773-4

18. Duffy CM, Colbert RA, Laxer RM, Schanberg LE, Bowyer SL (2005) Nomenclature and classification in chronic childhood arthritis: time for a change? Arthritis Rheum 52(2):382-385. https://doi.org/10.1002/art.20815

19. Zierhut M, Deuter C, Murray PI (2011) Classification of Uveitis - Current Guidelines. Eur Ophthalmol Rev 77(8)

20. Watad A, Azrielant S, Bragazzi NL, Sharif K, David P, Katz I, Aljadeff G, Quaresma M, Tanay G, Adawi M, Amital H, Shoenfeld Y (2017) Seasonality and autoimmune diseases: the contribution of the four seasons to the mosaic of autoimmunity. J Autoimmun 82:13-30. https://doi.org/10.1016/j.jaut.2017.06.001

21. Lieberman D, Lieberman D, Porath A (1996) Seasonal variation in community-acquired pneumonia. Eur Respir J 9(12):2630-2634. https://doi. org/10.1183/09031936.96.09122630

22. Moore M (1982) Centers for disease control. Enteroviral disease in the United States, 1970-1979. J Infect Dis 146(1):103-108. https://doi.org/10.1093/infdis/146.1.103

23. Smatti MK, Cyprian FS, Nasrallah GK, Al Thani AA, Almishal RO, Yassine HM (2019) Viruses and Autoimmunity: A Review on the Potential Interaction and Molecular Mechanisms. Viruses 11(8):762

24. Kimlin MG, Lucas RM, Harrison SL, van der Mei I, Armstrong BK, Whiteman DC, Kricker A, Nowak M, Brodie AM, Sun J (2014) The contributions of solar ultraviolet radiation exposure and other determinants to serum 25hydroxyvitamin D concentrations in Australian adults: the AusD study. Am J Epidemiol 179(7):864-874. https://doi.org/10.1093/aje/kwt446

25. Murdaca G, Tonacci A, Negrini S, Greco M, Borro M, Puppo F, Gangemi S (2019) Emerging role of vitamin D in autoimmune diseases: an update on evidence and therapeutic implications. Autoimmun Rev 18(9):102350. https://doi.org/10.1016/j.autrev.2019.102350

26. Sobrin L, Stanwyck LK, Pan W, Hubbard RA, Kempen JH, VanderBeek BL (2018) Association of Hypovitaminosis D with Increased Risk of uveitis in a large health care claims database. JAMA Ophthalmol 136(5):548-552. https://doi.org/10.1001/jamaophthalmol.2018.0642

27. Mosmann TR, Cherwinski H, Bond MW, Giedlin MA, Coffman RL (1986) Two types of murine helper T cell clone. I. Definition according to profiles of lymphokine activities and secreted proteins. J Immunol 136(7):2348-2357

28. Singh VK, Mehrotra S, Agarwal SS (1999) The paradigm of Th1 and Th2 cytokines: its relevance to autoimmunity and allergy. Immunol Res 20(2): 147-161. https://doi.org/10.1007/BF02786470

29. Steinman $L$ (2007) A brief history of $\mathrm{TH} 17$, the first major revision in the TH1/TH2 hypothesis of T cell-mediated tissue damage. Nat Med 13(2):139145. https://doi.org/10.1038/nm1551

30. Krishna MT, Subramanian A, Adderley NJ, Zemedikun DT, Gkoutos GV, Nirantharakumar K (2019) Allergic diseases and long-term risk of autoimmune disorders: longitudinal cohort study and cluster analysis. Eur Respir J 54(5)

31. Horton DB, Shenoi S (2019) Review of environmental factors and juvenile idiopathic arthritis. Open Access Rheumatol 11:253-267. https://doi.org/1 0.2147 /OARRR.S165916

32. Hayworth JL, Turk MA, Nevskaya T, Pope JE (2019) The frequency of uveitis in patients with juvenile inflammatory rheumatic diseases. Joint Bone Spine 86(6):685-690. https://doi.org/10.1016/j.jbspin.2019.06.001

\section{Publisher's Note}

Springer Nature remains neutral with regard to jurisdictional claims in published maps and institutional affiliations. 